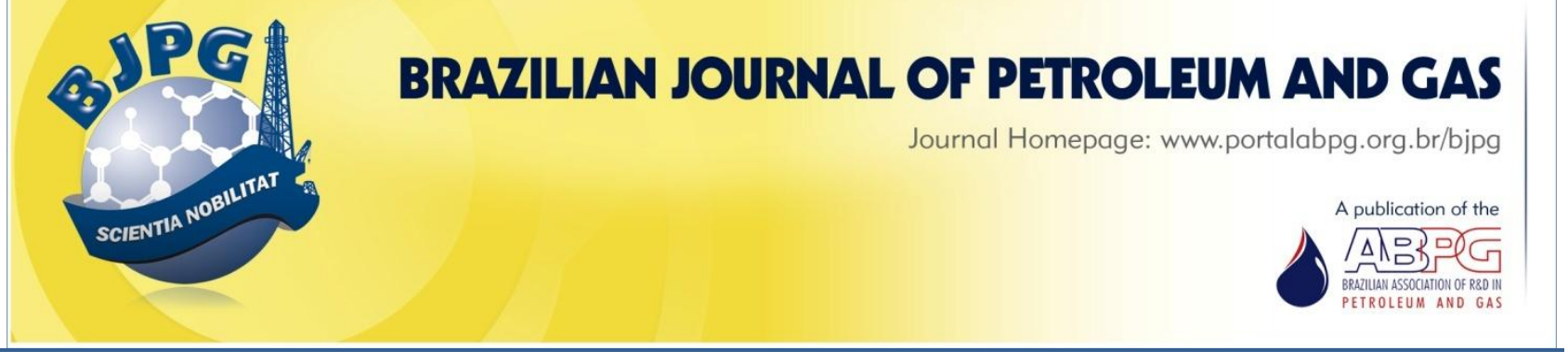

\title{
RHEOLOGY CHARACTERIZATION OF WATER-IN-OIL EMULSIONS
}

\author{
${ }^{\text {a }}$ Silva, P. H. L. ${ }^{1} ;{ }^{\text {a }}$ Naccache, M. F.; ${ }^{\text {a }}$ Mendes, P. R. S. \\ a Department of Mechanical Engineering, Pontifical Catholic University of Rio de Janeiro (PUC-Rio), Rio de Janeiro - RJ, Brazil \\ Received: 16.01 .2020 / Revised: 04.06.2020 / Accepted: 08.06.2020 / Published on line: 06.10.2020
}

\section{ABSTRACT}

One of the main problems of the oil industry is hydrate formation. Hydrates of natural gas are crystalline solids, formed by the association of water molecules and molecules of certain gas in an organized structure. Its occurrence is a natural concern for the Oil \& Gas Industry, given the potential risk of flow assurance. Nevertheless, ever-challenging scenarios encourage the search for risk assessment methodologies seeking to identify conditions where hydrates will form, but with little possibility of plugging. The present study aims to develop a water-in-oil emulsion capable of giving hydrate at ambient pressure. This work analyzes the effects of water and surfactant concentration in viscosity, storage, and dissipation modulus in a model water-in-oil emulsion. Rheological data are obtained for several combinations of emulsion components, and their mechanical behavior is related to hydrate formation.

\section{KEYWORDS}

emulsions; rheology; hydrates; rheometry

\footnotetext{
${ }^{1}$ To whom all correspondence should be addressed.

Address: Pontifical Catholic University of Rio de Janeiro (PUC-Rio), Department of Mechanical Engineering, Rua Marquês de São Vicente 225, Rio de Janeiro - RJ, Brazil.

ZIP Code: 22451-900 | Phone number: +55 83 99981-6820 | e-mail: phlimasilva@gmail.com doi:10.5419/bjpg2020-0011
} 


\section{INTRODUCTION}

Brazil is a major oil producer, with most of its production, about ninety-five percent (95\%), derived from the sea (ANP, 2018). Faced with this frontier, major challenges arise daily in oil production from the sea, especially deep and ultradeep water depths. Shallow, deep, and ultra-deep water depths are defined as those up to $300 \mathrm{~m}$, between $300 \mathrm{~m}$ and $1000 \mathrm{~m}$, and above $1000 \mathrm{~m}$, respectively (Ferreira Filho, 2016).

This production is drained through pipes called production lines. A common problem that can occur due to particular low temperature and highpressure, characteristics of areas where these production lines operate, is the emergence of hydrates. On average, the seabed temperature in the Atlantic Ocean is approximately $4^{\circ} \mathrm{C}$ (Marins et al., 2010).

In addition to the conditions of low temperature and high pressure, other variables may influence hydrate formation, such as composition of the fluid flowing into the system, agitation, contact surface for crystal formation, possibility of agglomeration, and salinity (Sloan \& Koh, 2008; Koh et al., 2011).

The hydrate formation can cause clogging of the production lines, generating unscheduled interruptions in operations, for example, during drilling and completion of wells (Santos, 2006). Besides clogging of production lines, hydrate formation can cause equipment damage and compromise the security of the facility. Similarly, in many cases, it is necessary to completely disrupt drilling operations or production to remove these hydrates, which generate major financial losses (Buzatoiu et al. 1999; Baptista, 2007).

Hydrates of natural gas are crystalline solids, formed by the association of water molecules and molecules of certain gas in an organized structure (Sloan \& Koh, 2008). Its occurrence is a natural concern for the Oil \& Gas Industry. Nevertheless, ever changing scenarios encourage the search for risk assessment methodologies to identify conditions where hydrates will form, but with little possibility of plugging. In this context, the understanding of hydrate rheology is a key element. The first step in comprehending hydrate rheology is evaluating the rheological properties of a model fluid.
In this work, we analyze the effects of water and surfactant concentration on viscosity, storage, and dissipation module in a water-in-oil emulsion. Rheological data obtained for various combinations of the components of the emulsion and their mechanical behavior is related. This study has the differential of deepening the knowledge of this phenomenon through rheological analyses, following a method that is based on rheological and image analyses to evaluate data of water-in-oil emulsions that can generate hydrates at ambient pressure.

\section{MATERIALS AND METHODS}

\subsection{Emulsion preparation}

Water-in-oil emulsions with water volume fraction (or water cut, as commonly denoted in the oil industry) ranging from 20 to $40 \mathrm{vol} \%$ are prepared using Shell Morlina S2 BL 10 and Shell Morlina S2 B 150, with reported kinematic viscosities of $10 \mathrm{~mm}^{2} \mathrm{~s}^{-1}$ and $150 \mathrm{~mm}^{2} \mathrm{~s}^{-1}$ at $40{ }^{\circ} \mathrm{C}$, and density of $0.881 \mathrm{~g} . \mathrm{cm}^{-3}$ and $0.887 \mathrm{~g} . \mathrm{cm}^{-3}$ at 15 ${ }^{\circ} \mathrm{C}$, respectively. The choice of oils and surfactants in the study was due to the ease of obtaining them from suppliers and for presenting physicochemical characteristics of interest in this study.

In all cases, emulsifier agents are composed of a nonionic-anionic surfactant mixture. Two surfactant concentrations are studied and reported here: $1 \%$ wt and $5 \%$ wt surfactant blend with respect to the total emulsion system. Deionized water is used as the aqueous phase in all emulsions. The composition of the surfactant mixture is $90 \% \mathrm{wt}$ and Sorbitan monooleate (Span 80, MW $428.61 \mathrm{~g} / \mathrm{mol}$, Sigma Aldrich) and 10\% wt sodium di-2-ethylhexylsulfosuccinate (AOT, MW $444.56 \mathrm{~g} / \mathrm{mol}$, Fisher Scientific). Their molecular structures are shown in Figure 1.

This surfactant mixture is suitable to produce oil continuous emulsions. This is supported by Bancroft's rule, stating that, in any emulsion, the external (continuous) phase is the one that solubilizes the surfactant (Bancroft, 1913; 1915).

Furthermore, the major component of the surfactant mixture, Span 80 , is a surfactant with a hydrophilic lipophilic balance (HLB) value of 4.3 . The HLB is a measure of the surfactant 


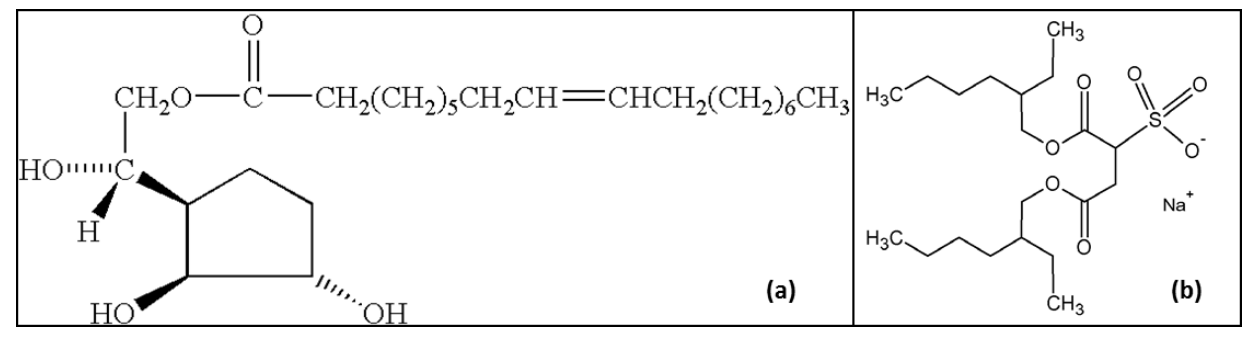

Figure 1. Molecular structure for surfactants: (a) sorbitan monooleate (Span 80); (b) sodium di-2ethylhexylsulfosuccinate (AOT).

hydrophilicity, which is defined as $1 / 5$ the weight percent of ethylene oxide in the molecule (Griffin, 1949; 1954).

Generally, surfactants with HLB values between 4 and 6 will produce water-in-oil emulsifiers (Griffin, 1949). The emulsions are prepared by dissolving the surfactant mixture in mineral oil by use of a magnetic stirrer and low heating $\left(\sim 50^{\circ} \mathrm{C}\right)$. For all water cuts, the mixture is stirred with a highspeed homogenizer at $8000 \mathrm{rpm}$ for $10 \mathrm{~min}$, while water is slowly added during the first minute. After preparation, the emulsions are poured into $200-\mathrm{mL}$ glass flask (Delgado-Linares, 2013).

\subsection{Interfacial tension measurements}

In this study, we used the Tensiometer - Lauda model platinum ring for measuring the interfacial tension of water-mineral oil interfacial tension (IFT). All measurements were made using the Du Nouy ring of the method (McClements, 1999). First, $20 \mathrm{~mL}$ of water was placed in a $50 \mathrm{~mL}$ beaker. Then, the ring was dipped approximately $1 \mathrm{~cm}$ into the water. Following, $20 \mathrm{ml}$ of oils with surfactants were placed carefully on the water. At last, the measurements were performed.

\subsection{Emulsion characterization}

With the purpose of observing the relationship between viscosity and water cut, viscosity measurements were performed at ambient pressure on the emulsions by use of a Anton Paar rheometer Physica MCR301 and Physica MCR501. In this study, Cross Hatched geometry was used with a gap size of $1 \mathrm{~mm}$ for Shell Morlina S2 B 150 emulsions, and Double Gap - DG geometry for Shell Morlina S2 BL 10 emulsions.

According to Mezger's work (Mezger, 2015), the choice of geometry is due to some factors related to the fluid to be studied, such as viscosity, whether it has suspended particles, density, amount of available sample, and if its water based or oil based. When the fluid has a very low viscosity, the most suitable geometry is that of concentric cylinders (couette), where the fluid will have a larger contact area with the geometry, implying a higher sensitivity. However, some precautions should be taken, such as sedimentation or particulate fluids that may interfere with the results (Mezger, 2015).

On the other hand, such difficulty is not found in parallel plate and grooved plate geometry, but for such geometries, a correction should be applied, since the shear rate is not constant throughout the geometry (Mezger, 2015).

Viscosity measurements are conducted at room temperature $\left(\sim 20^{\circ} \mathrm{C}\right)$. Measurements are performed at shear rates ranging from $0.01 \mathrm{~s}^{-1}$ to $100 \mathrm{~s}^{-1}$. In each test, 6 viscosity points per decade on a log scale were taken at steady state. The marking of each time point from the previous test was obtained using the steady shear rate (Constant Shear Rate) test. This test was set to run for 10 minutes, and the lowest rate of shear was applied from $0.01 \mathrm{~s}^{-1}$ to determine how long the emulsions enter steady state.

\subsection{Parallel plates correction}

The geometry of parallel plates rheometer is used widely for a variety of materials such as polymer solutions, suspensions, dispersions, and emulsions. An advantage over the cone and plate, or concentric cylinder geometries is the ease of varying the gap, which is decisive in the case of systems with particles or droplets.

However, unlike the cone and plate, or concentric cylinder geometries, the strain rate is not constant along the radius. Thus, both 
measured voltage and viscosity must be corrected (Figure 2). The equation is the WeissenbergRabinowitsch dependence of shear rate of nonNewtonian fluids correcting stress (Macosko, 1994). The rheometers (Phyica 301 and 501) used in this study measured viscosity and apparent shear stress, and it was necessary to make a correction.

Equations to correct the shear stress and viscosity:

$\tau_{12}(R)=\frac{M}{2 \pi R^{3}}\left[3+\frac{d \ln M}{d \ln Y_{R}}\right]=\frac{\tau_{a R}}{4}\left[3+\frac{d \ln M}{d \ln Y_{R}}\right]$

$\eta\left(\dot{\gamma}_{R}\right)=\frac{\tau_{R}}{\gamma_{R}^{\prime}}=\frac{\eta_{a}}{4}\left[3+\frac{d \ln M}{d \ln \dot{\gamma}_{R}}\right]$

Where: $\tau=$ shear stress; $M=$ torque; $\dot{\gamma}=$ shear rate; and $\eta=$ viscosity.

\section{RESULTS AND DISCUSSIONS}

\subsection{Interfacial tension and droplet size}

The calculation of each IFT oil phase with the respective concentration of surfactants was done using equation (3), since all other parameters of this formula are tabulated.

$\sigma_{L}=\left[a_{0}+\left(\frac{a_{1}+a_{2} \cdot \sigma_{\hat{i}}}{\rho_{L} \cdot \rho_{a y}}+a_{3}\right)^{0.5}\right]$.

$\cdot\left(\frac{g_{0}}{g_{1}}\right) \cdot\left(a_{4}+a_{5} \cdot \sigma_{i}\right)+a_{5} \cdot \sigma_{i}+a_{7} \cdot T_{L}+a_{8}$

Where:

$\sigma_{\mathrm{L}}=$ surface / interfacial tension of the liquid corrected in $\mathrm{mN} / \mathrm{m}$;

$\sigma_{i}=$ surface tension indicated on the multimeter in $\mathrm{V}$;

$\mathrm{T}_{\mathrm{L}}=$ liquid temperature in ${ }^{\circ} \mathrm{C}$;

$\rho_{\mathrm{L}}=$ specific mass of the liquid in $\mathrm{g} / \mathrm{cm}^{3}$;

$\rho_{\mathrm{ar}}=$ specific mass of air in $\mathrm{g} / \mathrm{cm}^{3}$;

$\mathrm{g}_{0}=$ gravity acceleration at the calibration site in $\mathrm{m} / \mathrm{s}^{2}$;

$\mathrm{g}_{1}=$ gravity acceleration at the place of use of the tensiometer $\mathrm{m} / \mathrm{s}^{2}$;

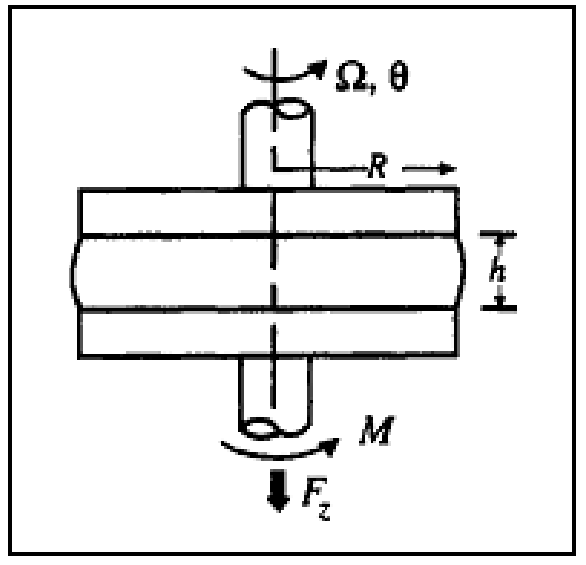

Figure 2. Parallel plate geometry (Macosco, 1994, p. 217). Where: $\Omega, \theta$ are the angular velocity; $F_{Z}$ is the normal force; $h$ is the distance between disks; $R$ is the ratio; and $M$ is the torque.

$a_{0}, a_{1}, a_{2}, a_{3}, a_{4}, a_{5}, a_{6}, a_{7}$, and $a_{8}$ are constants, and their respective values are:

$\mathrm{a}_{0}=0.7250$

$\mathrm{a}_{1}=0.00016853 \mathrm{~g} / \mathrm{m}^{3}$

$a_{2}=0.039955 \mathrm{~g} \cdot \mathrm{m}^{3} \cdot \mathrm{v}^{-1}$

$\mathrm{a}_{3}=0.012798$

$\mathrm{a}_{4}=0.417473 \mathrm{mN} / \mathrm{m}$

$a_{5}=98.972922 \mathrm{mN} \cdot \mathrm{m}^{-1} \cdot \mathrm{V}^{-1}$

$a_{6}=0.763219 \mathrm{mN} \cdot \mathrm{m}^{-1} \cdot \mathrm{v}^{-1}$

$a_{7}=-1.235590 \mathrm{mN} \cdot \mathrm{m}^{-1} \cdot{ }^{\circ} \mathrm{C}^{-1}$

$\mathrm{a}_{8}=24.841177 \mathrm{mN} / \mathrm{m}$

The results of Figure 3 show that in all oily phases studied, the interfacial tension value tends to stabilize just before $1 \%$, that is, with concentrations higher than this it no longer promotes significant changes in the interfacial tension value. This was the reason for the choice of $1 \%$ and $5 \%$ wt of surfactant concentration for the tests.

The mean droplet size for the emulsions with both $1 \%$ and $5 \%$ wt of surfactant is in the range $2-$ $10 \mu \mathrm{m}$ diameter, at room temperature $\left(\sim 20^{\circ} \mathrm{C}\right)$, for all water cuts studied in this work. These observations are in good agreement with other reported data for water-in-crude oil emulsions (Orciuch et al., 2012; Majid et al., 2015; Kolotova et al., 2017). In all cases, the droplet size is relatively similar for all water cuts. We also observed that the variation in droplet size for 


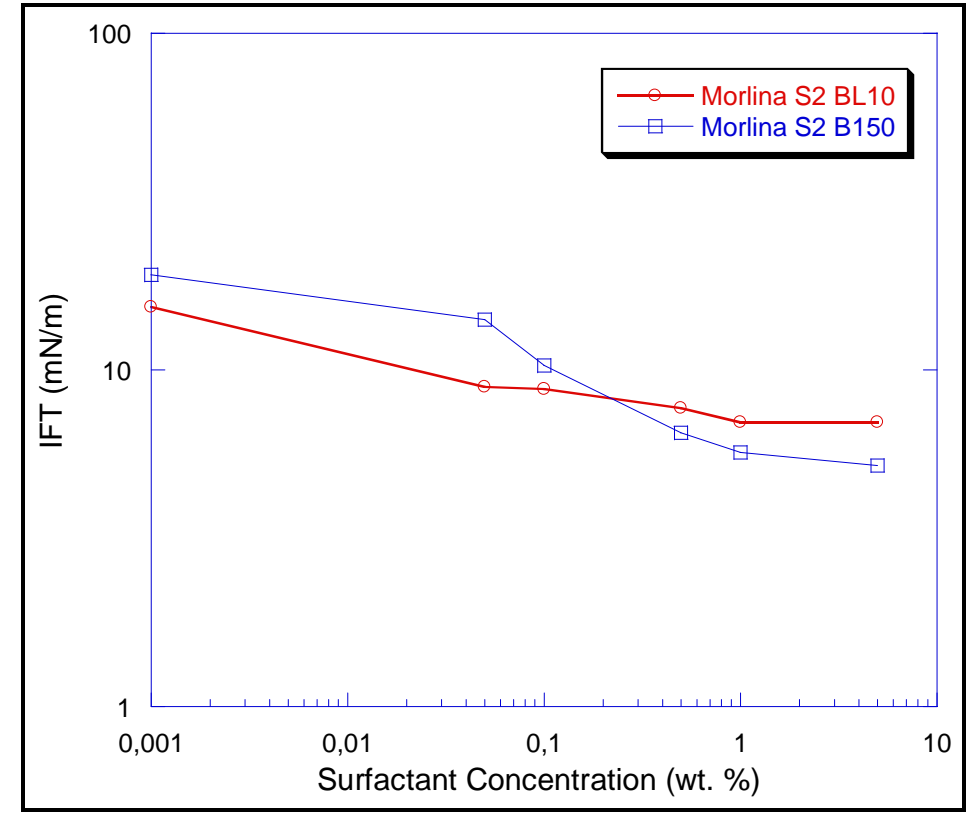

Figure 3. Interfacial tension as a function of surfactant concentration.

emulsions with $5 \%$ wt surfactant is similar to that with $1 \%$ wt surfactant. Figures 4 and 5 show examples of microscopic images of the appearance of the emulsions at $20 \%, 30 \%$, and $40 \%$ water cuts 1 day after their preparation for emulsions with $1 \%$ and $5 \%$ wt surfactant.

\subsection{Viscosity results}

\subsubsection{Shell Morlina S2 BL 10}

Viscosity profiles for emulsions prepared with
$1 \%$ and $5 \%$ wt of surfactant measured at ambient pressure in temperature of $20^{\circ} \mathrm{C}$ are presented in Figure 6 . The apparent viscosity of the emulsions increases with the water cut, for Shell Morlina S2 $B L 10$. This increase in apparent viscosity is due to the increase in packing of the water droplets.

Since the viscosity of the emulsion is proportional to the viscosity of the external phase, the viscosity of the emulsion will deviate further from the viscosity of mineral oil Shell Morlina S2 BL 10 as the water cut increases. Furthermore, shear-

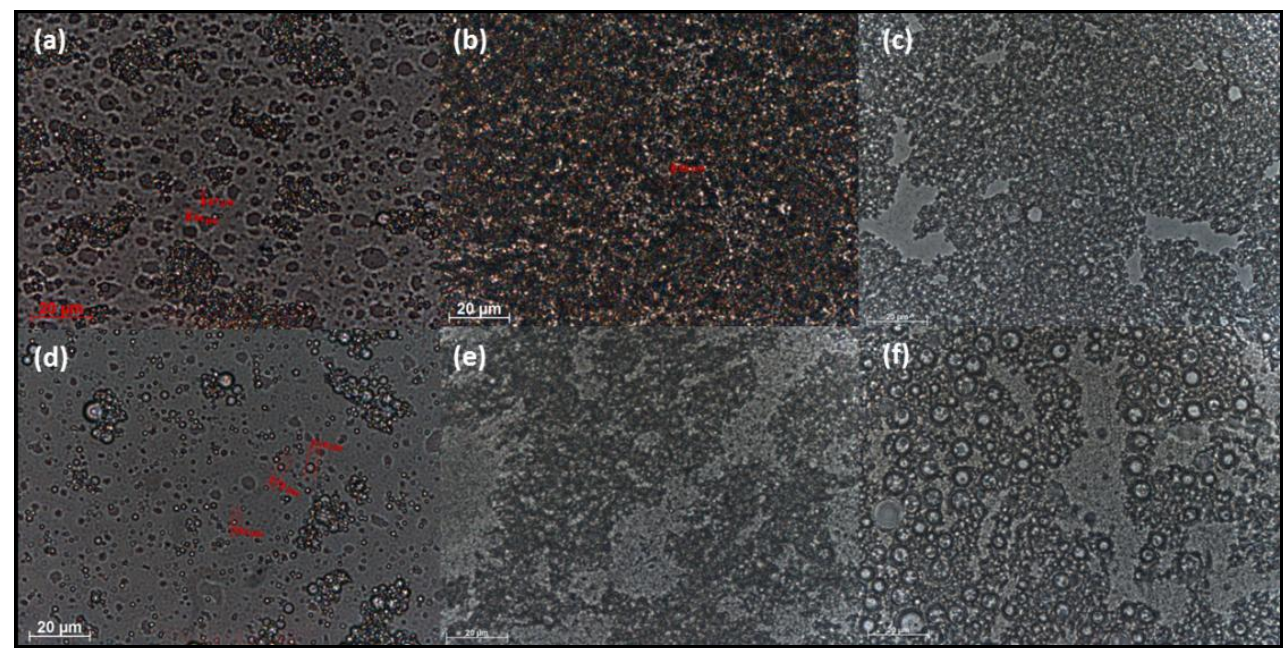

Figure 4. Shell Morlina S2 BL 10 sample microscope images of water-in-oil emulsions: $1 \%$ wt surfactant with: (a) 20 water vol \%, (b) 30 water vol \%, and (c) 40 water vol \%; 5\% wt surfactant with: (d) 20 water vol \%, (e) 30 water vol \%, and (f) 40 water vol \%. 


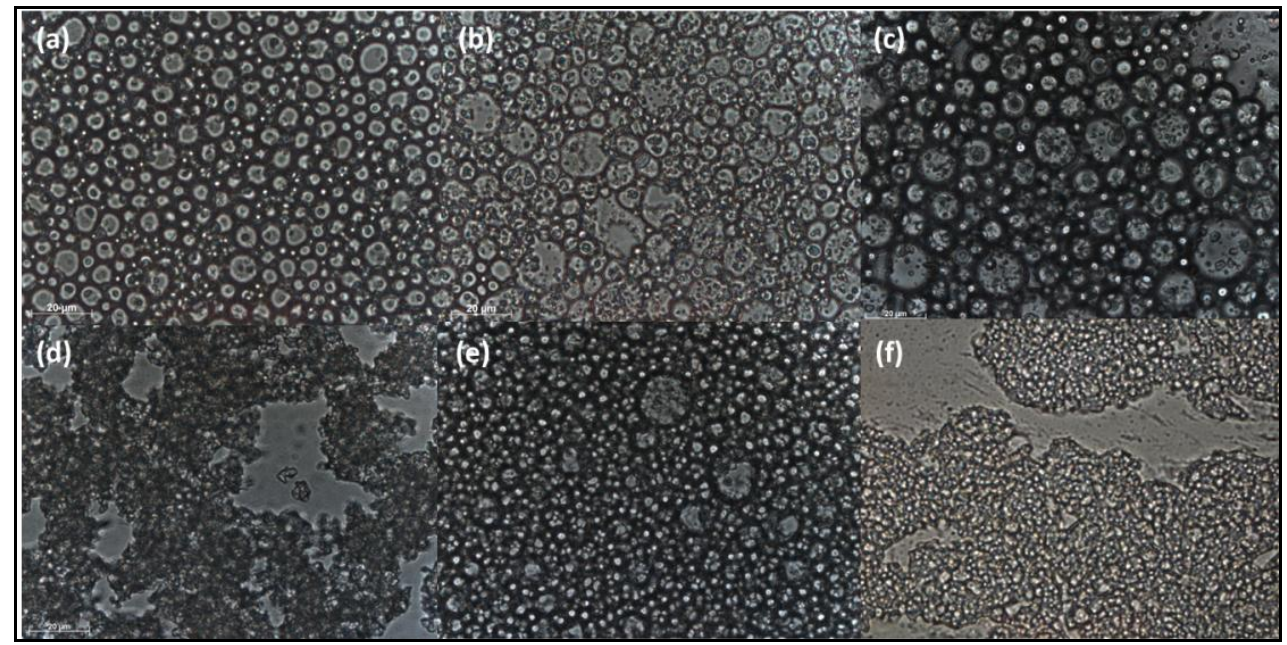

Figure 5. Shell Morlina S2 B 150 sample microscope images of water-in-oil emulsions: 1\% wt surfactant with: (a) 20 water vol \%, (b) 30 water vol \%, (c) 40 water vol \%; 5\% wt surfactant with: (d) 20 water vol \%, (e) 30 water vol $\%$, and (f) 40 water vol \%.
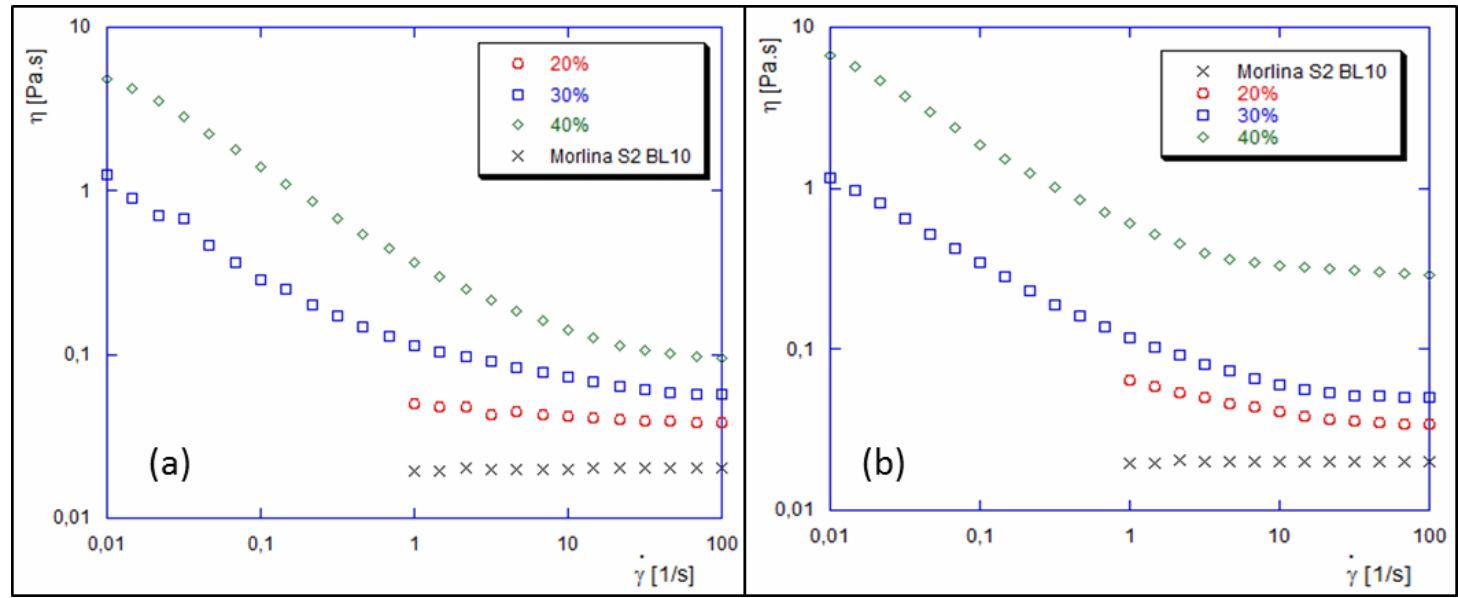

Figure 6. Viscosity profiles at various water cuts: (a) emulsion prepared with $5 \%$ wt surfactant at $20^{\circ} \mathrm{C}$, and (b) emulsion prepared with $1 \%$ wt surfactant at $20^{\circ} \mathrm{C}$.

thinning behavior was observed for both surfactant concentrations. This behavior is typical of complex dispersed systems such as human blood, food emulsions, and even water-in-crude oil emulsions; and can be attributed to, in emulsion cases, the rupture of clusters or droplet aggregates, followed by droplet alignment under shear (Izidoro et al., 2009; Cherrya \& Eaton, 2013; Ariffin et al., 2016).

Thus, the shear-thinning effect is more significant at higher water cuts and lower temperatures because the system becomes highly packed and the droplet-droplet interactions increase (Ariffin et al., 2016).
Furthermore, viscosity profiles at room temperature $\left(\sim 20^{\circ} \mathrm{C}\right)$ show that, for $20 \%$ and $30 \%$ vol water cuts, the viscosity of the emulsion is relatively similar for both surfactant concentrations (Figure 7). However, for 40 vol \% water cuts, the viscosity of the emulsion is slightly larger for the system with $1 \mathrm{wt} \%$ surfactant. The viscosity is related to the size and packing (concentration) of water droplet in the emulsion, and it is known that the increase in droplet-droplet interactions increases the viscosity of the emulsion.

A very different result was obtained in the Stress Sweep tests for all studied water cuts: $20 \%$, $30 \%$, and $40 \%$ for the system with $5 \%$ wt. 


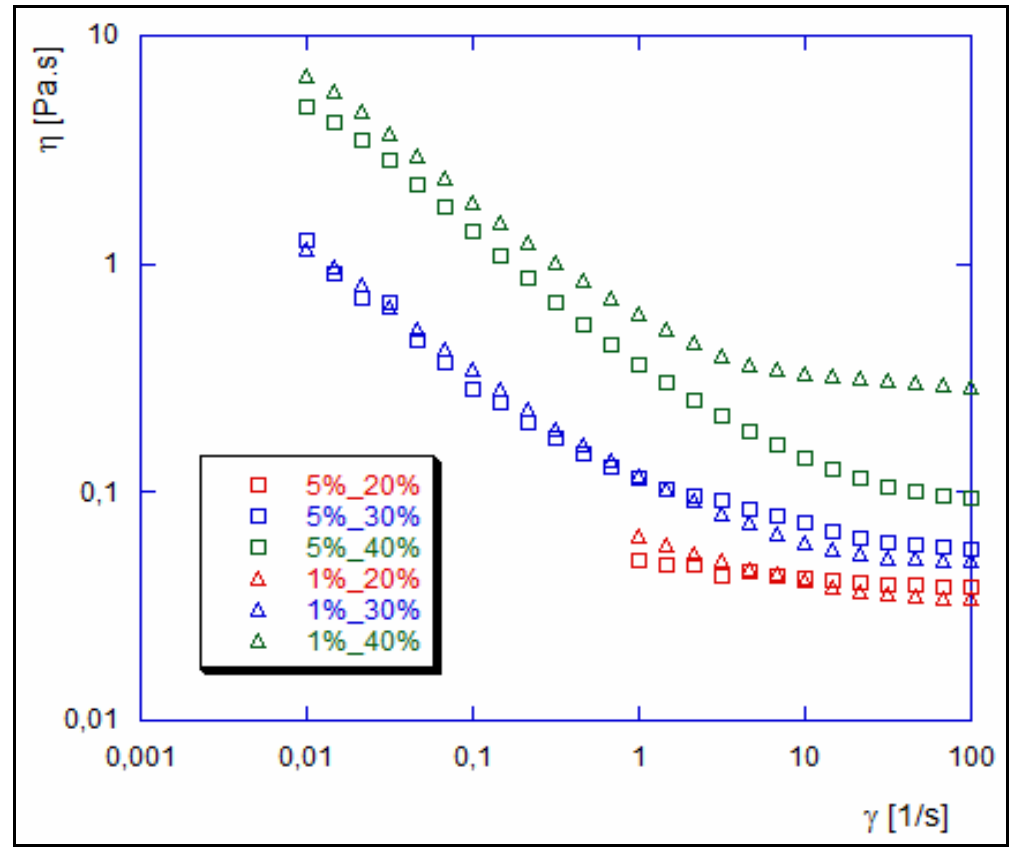

Figure 7. Flow Curves: emulsion prepared with $1 \%$ wt and $5 \%$ wt surfactant at $20^{\circ} \mathrm{C}$.
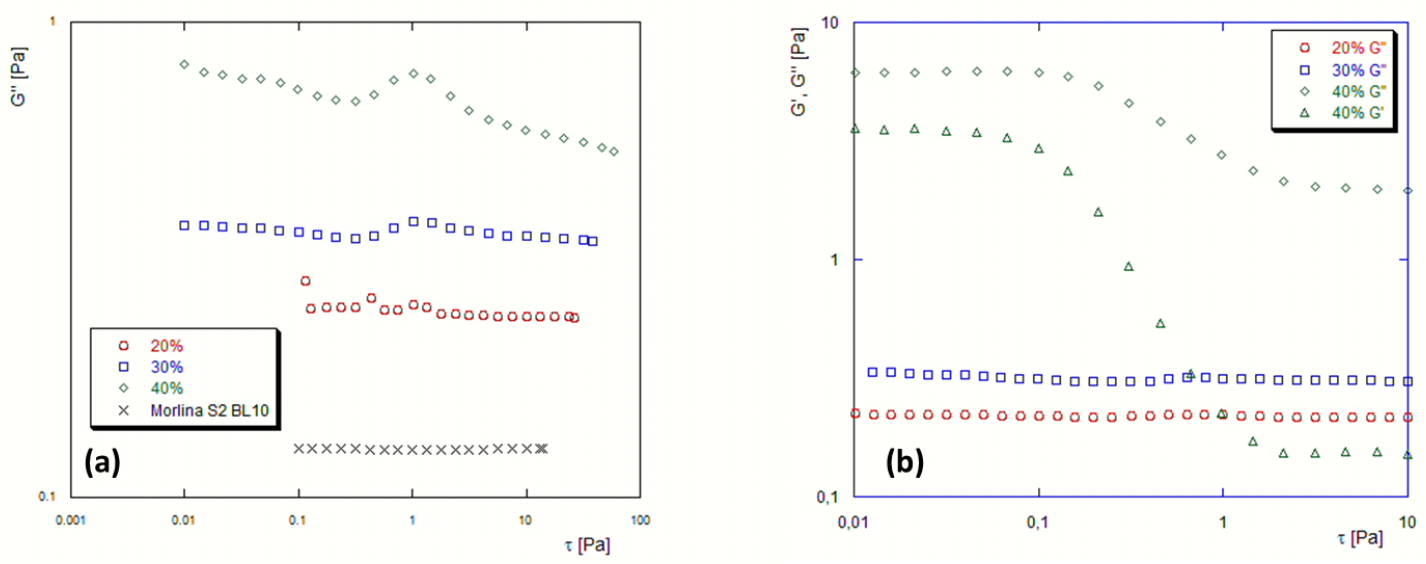

Figure 8. Stress Sweep tests: (a) emulsion prepared with $5 \%$ wt surfactant at $20^{\circ} \mathrm{C}$, and (b) emulsion prepared with $1 \%$ wt surfactant at $20^{\circ} \mathrm{C}$.

surfactant. The elastic or storage modulus $\mathrm{G}^{\prime}$ measured was either 0 (zero) or presented very small values of the order of $10^{-3}$. Therefore, Figure 8 (a) shows only the values of the viscous or loss modulus G". This result indicates that the emulsions found are fluids with purely viscous behavior, i.e. without elasticity.

A close result of emulsions prepared with $5 \%$ surfactants was obtained in the Stress Sweep tests
(Figure $8 b$ ). The difference was the $40 \%$ water cut, which showed elasticity, since the values obtained for the elastic or storage modulus $G^{\prime}$ were significant.

Such behavior can be justified by the low viscosity of the oil, coupled with the fact that the emulsions have a very small droplet size and water cuts are not so expressive as to cause the elastic modules to appear in the prepared emulsions. 


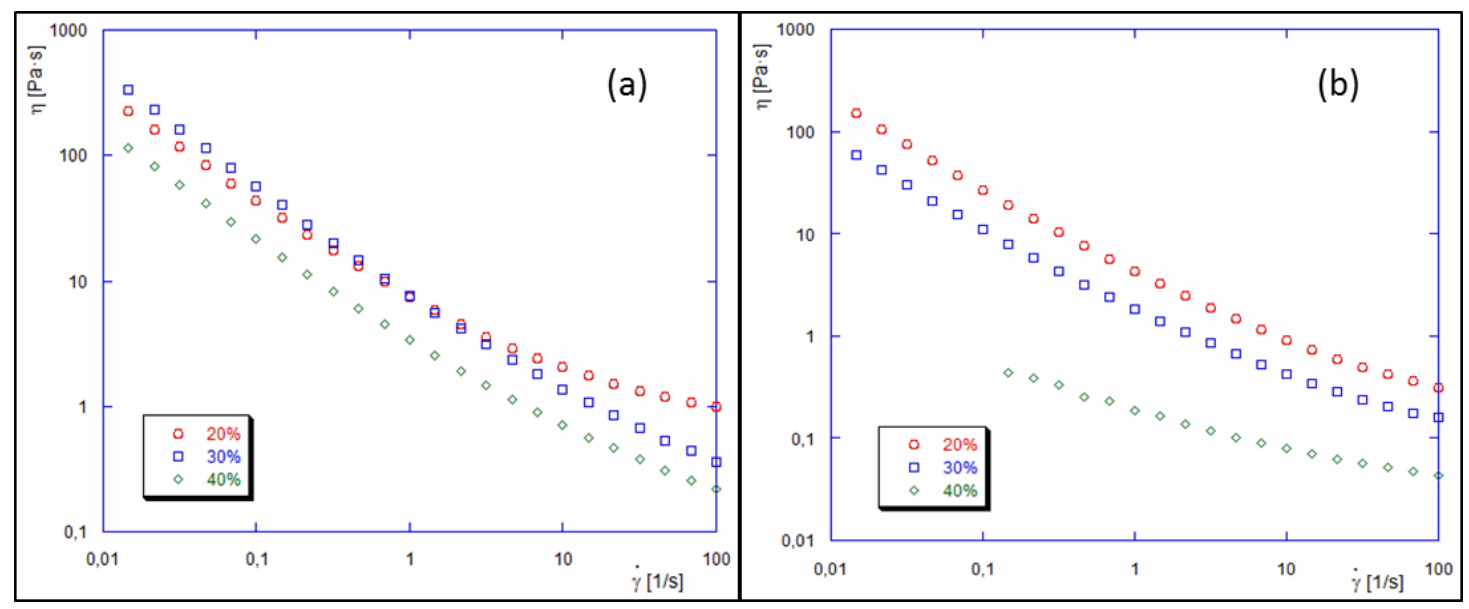

Figure 9. Viscosity profiles at various water cuts: (a) emulsion prepared with $5 \%$ wt surfactant at $20^{\circ} \mathrm{C}$, and (b) emulsion prepared with $1 \%$ wt surfactant at $20^{\circ} \mathrm{C}$.

\subsubsection{Shell Morlina S2 B 150}

Viscosity profiles for emulsions prepared with $1 \%$ and $5 \%$ wt surfactant measured at ambient pressure in temperature of $20^{\circ} \mathrm{C}$ are presented in Figure 9. As can be seen, the apparent viscosity of the emulsions decreases significantly with the water cut, for Shell Morlina S2 B 150 and 1\% wt of surfactants, and for $5 \%$ wt for surfactants this decrease is milder.

This reduction in viscosity due to phase inversion, as the water cut increased interaction of the surfactant with the oil, was not sufficient to maintain the emulsion as water in oil. This became more evident in the concentration of surfactant at $1 \%$ wt. Emulsions for this oil also present a shearthinning behavior, except for the emulsion with $40 \%$ water cut and $1 \%$ wt surfactants. The behavior of the emulsion with $40 \%$ water cut and $1 \%$ wt surfactant is best modeled by a power law fluid. This type of model presents a potential relationship without the presence of a yield stress, thus, it is simpler than other rheological models.

To verify that the prepared emulsions are water-in-oil, a drop test was performed. The drop test is a quick and simple way to determine if an emulsion is oil-in-water (O / W) or water-in-oil (W / O). A few drops of emulsion are poured into a test tube or beaker containing water and into another containing the oil used to make the emulsions. If the emulsion droplets get dispersed in the water sample and not in the sample oil, the emulsion is characterized as $\mathrm{O} / \mathrm{W}$. Likewise, an emulsion is deemed $\mathrm{W} / \mathrm{O}$ when the droplets are dispersed in this oil and remain intact in the test tube or beaker containing the aqueous phase. Figure 9 presents the results of the drop test.

A very interesting result was found after the drop test on emulsions prepared with Morlina S2 B 150 and $5 \%$ surfactants. Only the emulsion prepared with a $20 \%$ water cut did not dissolve in water (Figure 10a), suggesting that the other emulsions would have reversed their phase, that is, they could be oil-in-water emulsions. Rheological tests for Morlina S2 B 150 with 1\% wt surfactant (Figure 11) pointed to a viscosity reduction with increased water cut for emulsions prepared with $1 \%$ surfactant, indicating a probable phase inversion. In the drop test this result was confirmed because all emulsions, when dripped in water, dissolved (Figures 10d, 10e, and 10f).

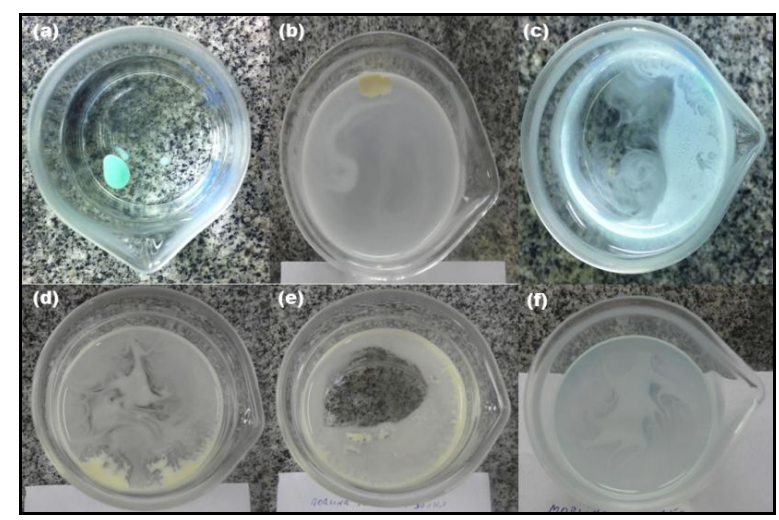

Figure 10. Drop test emulsions prepared with: $5 \%$ wt surfactants with (a) $20 \%$, (b) $30 \%$, and (c) $40 \%$ vol water cuts; and $1 \%$ wt surfactants with (d) $20 \%$, (e) $30 \%$, and (f) $40 \%$ vol water cuts. 


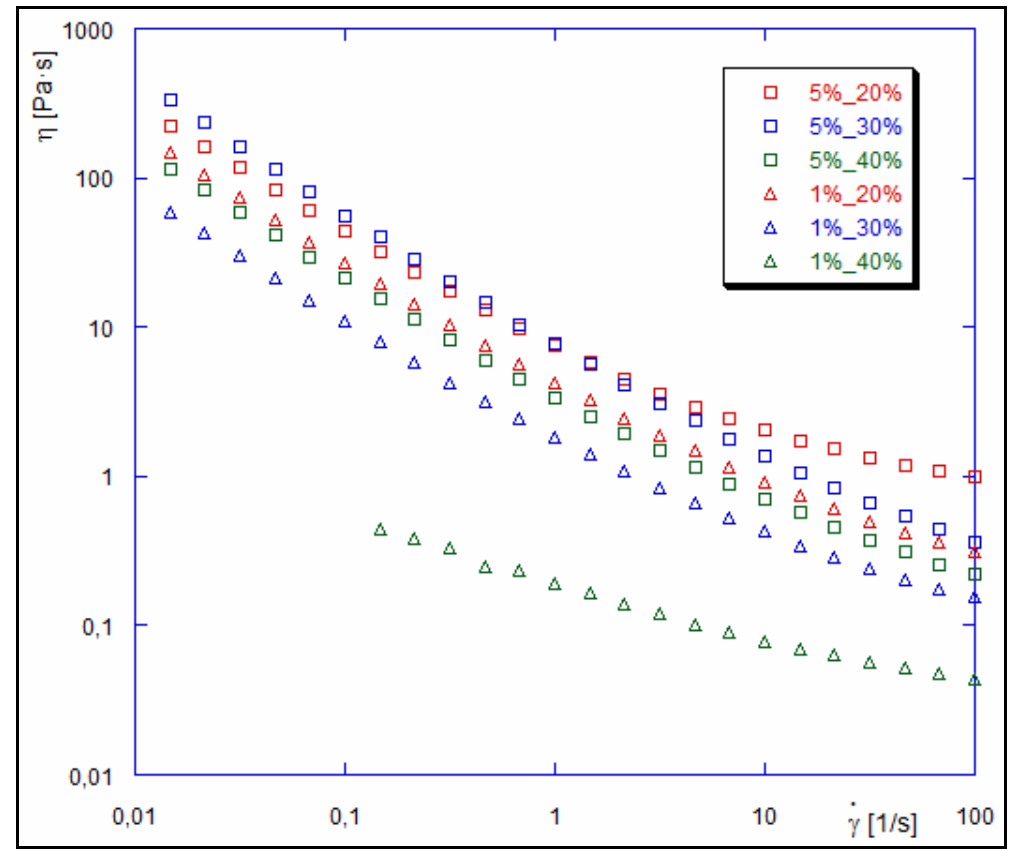

Figure 11. Flow Curves: emulsion prepared with $5 \mathrm{wt} \%$ and $1 \mathrm{wt} \%$ surfactant at $20^{\circ} \mathrm{C}$.

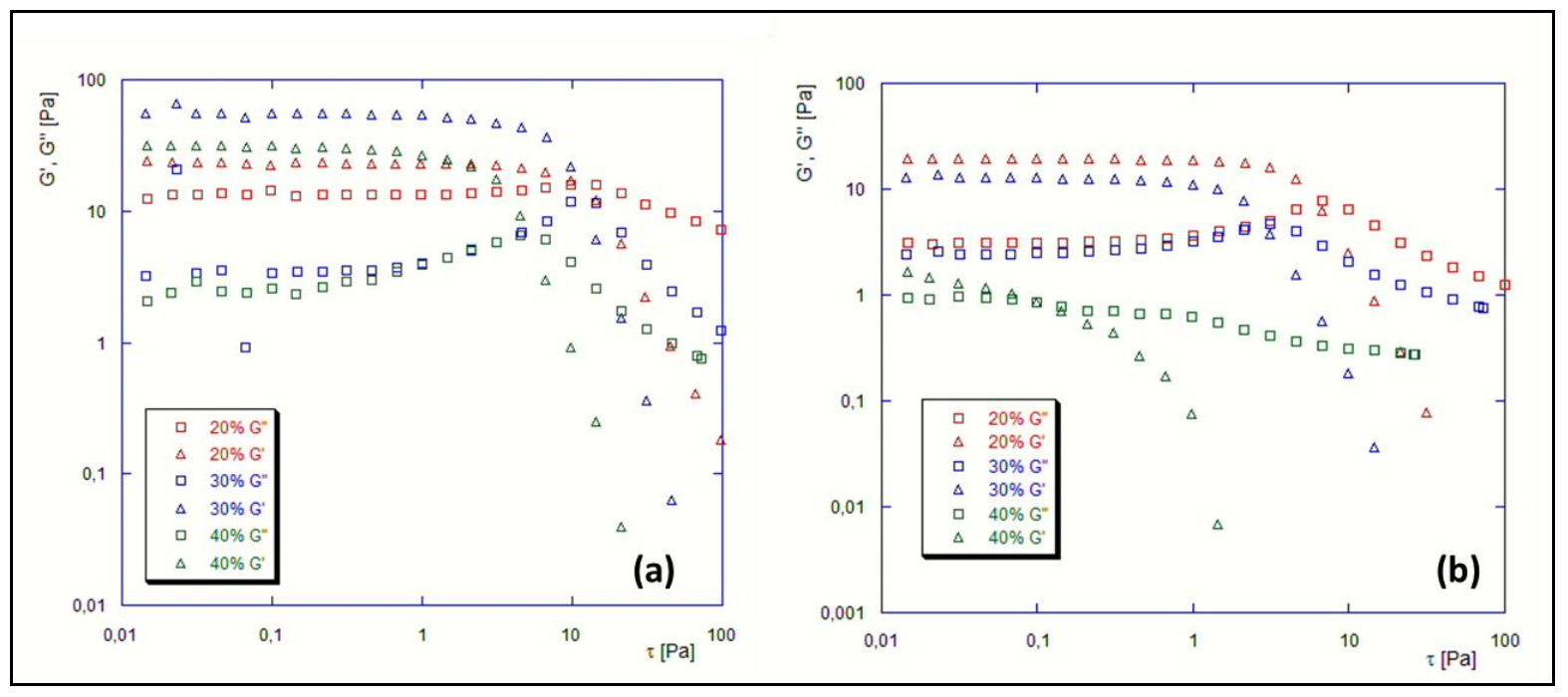

Figure 12. Stress Sweep tests: (a) emulsion prepared with $5 \%$ wt surfactant at $20^{\circ} \mathrm{C}$, and (b) emulsion prepared with $1 \%$ wt surfactant at $20^{\circ} \mathrm{C}$.

Unlike the previous oil, the Shell Morlina S2 B 150 presented very different results. As the water cut was increased, the variation between the results followed the same direction, that is, they increased more and more. This variation is due to the phase reversal. The higher the water cut, the emulsion became less viscous as the oil droplets were in smaller concentration.

An expected result was obtained in the Stress Sweep tests for the tests from $5 \%$ wt surfactants (Figure 12a), in all studied water cuts, 20\%, 30\%, and $40 \%$. The measured elastic or storage modulus G' was above the viscous, or loss modulus G" up to a certain stress. This confirms the yield curve behavior, where a yield stress was well defined for each water cut, approaching from 10Pa (Figure 12a).

Emulsions prepared with $1 \%$ wt of surfactants showed elastic or storage modulus $\mathrm{G}^{\prime}$ and viscous or loss modulus G" within the evaluated stress range. However, the $40 \%$ water cut test revealed a small region where the elastic or storage modulus 
G' value is greater than the viscous or loss modulus G". The yield stress for the $20 \%$ and $30 \%$ water cuts was approximately 7PA, showing a viscoelastic behavior for both surfactant concentrations.

\section{CONCLUSIONS}

The results for the oils were analyzed and contrasted. The Shell Morlina S2 BL 10 presented very low viscosity ( 0020 Pa.s), whereas Shell Morlina S2 B 150 displayed high viscosity ( 0.528 Pa.s). From visual tests, one can observe that the emulsions prepared with the Shell Morlina S2 BL 10 were more stable, at surfactant concentrations of $1 \%$ and $5 \%$, used by weight, of the emulsions prepared with Shell Morlina S2 B 150. While the first oil gave stable emulsions for more than a week, the second stable emulsions provided stability for only two days, despite the strong lipophilic interaction between surfactant molecules.

The time to perform the rheological tests was up to two days, so the stability of the emulsions was not relevant to interference factor in these results.

This study took into consideration the size of droplets presented, obtained by means of microscopy images, a factor that also influences the stability of emulsions. The emulsions prepared with the Shell Morlina S2 BL 10 showed an average droplet size between 0.5 and $2 \mu \mathrm{m}$, whereas the emulsions prepared with Shell Morlina S2 B 150 presented droplets with size between 3 and $10 \mu \mathrm{m}$, noting that the only water-in-oil emulsion with Shell Morlina S2 B 150 is prepared with $5 \%$ by weight of surfactant and $20 \%$ water cut.

Viscosity measurements showed dependency on the water cut in both oils having a shear thinning behavior. In addition, Shell Morlina S2 B 150 showed a wide variation in results between the two concentrations of surfactants used in this study.

Stress Sweep tests showed that emulsions prepared with Shell Morlina S2 BL 10 did not have elasticity, while emulsions prepared with Shell Morlina S2 B 150 showed elasticity, with welldefined linear viscoelastic regions, suggesting a yield stress.

\section{REFERENCES}

ANP - Agência Nacional do Petróleo, Gás Natural e Biocombustíveis - ANP. Relatório: Produção Nacional de Petróleo e Gás Natural - Anuário estatístico brasileiro do petróleo, gás natural e biocombustíveis: Rio de Janeiro, 2018. Available at: http://www.anp.gov.br/publicacoes/anuarioestatistico/anuario-estatistico-2018. Accessed on: 24 October 2019. (in Portuguese).

Ariffin; T. S. T.; Yahya, E.; Husin, H. The rheology of light crude oil and water-in-oil-emulsion. Procedia Engineering, v.148, p.1149-1155, 2016. https://doi.org/10.1016/j.proeng.2016.06.614

Bancroft, W. D. The Theory of Emulsification V. Journal of Physics Chemistry, v. 17(6), p. 501-519, 1913. https://doi.org/10.1021/j150141a002

Bancroft, W. D. The theory of emulsification, VI. Journal of Physics Chemistry, v. 19, p. 275-309, 1915. https://doi.org/10.1021/j150157a002

Baptista, J. M. M. Análise da formação de hidratos em atividades de perfuração de campos petrolíferos. Monografia (Projeto Final). Departamento Acadêmico de Mecânica, Universidade Tecnológica Federal do Paraná, 2007. (in Portuguese).

Buzatoiu, B.; Popp, V. V.; Loas, I. R. Hydrate problem in the oil production industry. Society of Petroleum Engineers - SPE. In: International Symposium on Oilfield Chemistry. Houston, Texas. 1999. p. 475 - 483. https://doi.org/10.2118/50749-MS

Cherrya, Erica M.; Eaton, J. K. Shear thinning effects on blood flow in straight and curved tubes. Physics of Fluids, v. 25(7), 073104, 2013. https://doi.org/10.1063/1.4816369

Delgado-Linares, J. G.; Majid, A. A. A.; Sloan, E. D.; Koh, C. A.; Sum, A. K. Model water-in-oil emulsions for gas hydrate studies in oil continuous systems. Energy Fuels, v. 27, p. 4564-4573, 2013. https://doi.org/10.1021/ef4004768

Ferreira Filho, V. J. M. Gestão de operações e logística na produção de petróleo: Fundamentos, Metodologia e Modelos Quantitativos. 1a $\mathrm{ad}$. Editora: Elsevier/Campus. 2016. (in Portuguese). 
Griffin, W. C. Classification of surface-active agents by "HLB". Journal of Cosmetic Science, v.1, p. 311-326, 1949.

Griffin, W. C .J. Calculation of HLB values of nonionic surfactants. Journal of Cosmetic Science, v. 5, p. 249-256, 1954.

Izidoro, D. R.; Scheer, A. P.; Sierakowsk, M. R. Rheological properties of emulsions stabilized by green banana (Musa cavendishii) pulp fitted by power law model. Brazilian Archives of Biology and Technology, v. 52(6), p. 1541-1553, 2009. https://doi.org/10.1590/S1516-89132009000600026

Koh, C. A.; Sloan, E.D.; Sum A.K.; Wu, D.T. Fundamentals and applications of gas hydrates. Annual Review of Chemical and Biomolecular Engineering, v.2, p. 237-57, 2011. https://doi.org/10.1146/annurev-chembioeng-061010$\underline{114152}$

Kolotova, D.; Brichka, K.; Simonsen, G.; Simon, S. C.; Derkach, S.; Paso, K. G.; Sjöblom, J. Droplet crystallization in water-in-crude oil emulsions: Influence of salinity and droplet size. Energy \& Fuels, v. 31(7), p. 7673-7681, 2017.

https://doi.org/10.1021/acs.energyfuels.7b00777

Macosko, C. W. Rheology: principles, measurements and applications. New York: WILEYVCH Publishers, 1994, 568p.

Majid, A. A. A; Saidian, M.; Prasad, M.; Koh, C. A. Measurement of the water droplet size in water-inoil emulsions using low field nuclear magnetic resonance for gas hydrate slurry applications. Canadian Journal of Chemistry, v. 93(9), p. 10071013, 2015. https://doi.org/10.1139/cjc-2014-0608
Marins, R. V.; Cavalcante, J. P. S.; Sohn, C. D.M.; Bittencourt, L. Glossário de Oceanografia Abiótica. Fortaleza, Brazil: Universidade Federal do Ceará LABOMAR/NAVE, 2010, 144p. (In Portuguese)

McClements, D. J. Food Emulsions: Principles, Practice, and Techniques. Florida: CRC Press, 1999, $378 p$.

Mezger, T. G. Applied Rheology. Austria: Anton Paar GmgH, $1^{\text {st }}$ edition, 2015, 191p.

Orciuch, W.; Makowski, L.; Moskal, A.; Gradon, L. Evolution of the droplets size during a two-phase flow through a porous media: Population balance studies. Chemical Engineering Science, v. 68, p. 227- 235, 2012.

https://doi.org/10.1016/i.ces.2011.09.034

Santos, O. L. A. Segurança de Poço em Lâminas de Água Ultra profundas. In: Encontro Nacional de Hidráulica de Perfuração e Completação de Poços de Petróleo e Gás, Proceedings ENAHPE'2006, Domingos Martins. 2006. 7p.

Sloan, E. D.; Koh, C. A. Clathrate Hydrates of Natural Gases. Florida: CRC Press: $3^{\text {rd }}$ ed., 2008, 752p. https://doi.org/10.1201/9781420008494 